\title{
Comparison of Electrospray Ionization, Atmospheric Pressure Chemical Ionization, and Atmospheric Pressure Photoionization for the Analysis of Dinitropyrene and Aminonitropyrene LC-MS/MS
}

\author{
Ellen A. Straube, Wolfgang Dekant, and Wolfgang Völkel \\ Department of Toxicology, University of Würzburg, Würzburg, Germany
}

\begin{abstract}
The only relevant source for human exposure to dinitropyrenes is diesel engine emissions. Due to this specificity, dinitropyrenes may be used as biomarkers for monitoring human exposure to diesel engine emissions. Only few analytical methods have been described for the quantitation of dinitropyrenes and their metabolites, aminonitropyrenes, and diaminopyrenes. Therefore, for dinitropyrenes, aminonitropyrenes, and diaminopyrenes were selected as model compounds for the development of a sensitive HPLC-MS/MS method (high performance liquid chromatography coupled to triple quadrupole mass spectrometry) was to quantify polyaromatic amines and nitroarenes in biological matrices was developed optimal methods by comparing electrospray ionization (ESI), atmospheric pressure chemical ionization (APCI), and atmospheric pressure photoionization (APPI) sources. Dinitropyrene was not effectively ionized and diaminopyrene yielded mainly $[\mathrm{M}]^{+}$ions by electrospray ionization. With APCI and APPI, precursor ions of diaminopyrene and aminonitropyrene were $[\mathrm{M}+\mathrm{H}]^{+}$and $[\mathrm{M}]^{-}$ for dinitropyrene. Precursor ions with $[\mathrm{M}-30]^{-}$for dinitropyrene and $[\mathrm{M}-30+\mathrm{H}]^{+}$for aminonitropyrene were observed. Reversed and normal phase HPLC-MS/MS with ESI, APCI and APPI were optimized separately with respect to unequivocal analyte identification and sensitivity. Normal phase HPLC coupled to APPI-MS/MS gave the highest precision and sensitivity for aminonitropyrene $(6 \% / 0.2 \mathrm{pg}$ on column) and dinitropyrene $(9 \% / 0.5 \mathrm{pg}$ on column). The limit of detection in spiked rat plasma was $5 \mathrm{pg} / 100 \mu \mathrm{L}$ for aminonitropyrene (accuracy $82 \%$ ) and $10 \mathrm{pg} / 100 \mu \mathrm{L}$ for dinitropyrene (accuracy 105\%). In plasma of rats treated with dinitropyrene by oral administration, no detectable levels of dinitropyrene but higher aminonitropyrene levels compared with intratracheal instillation were observed. These findings clearly demonstrate that dinitropyrene was absorbed after oral and intratracheal application and that a reduction of nitro groups occurs to a high extent in the reductive environment of the intestine. To our knowledge, this is the first time that aminonitropyrene was observed in plasma after intratracheal or oral administration directly demonstrating the reductive metabolism of dinitropyrene in vivo. (J Am Soc Mass Spectrom 2004, 15, 1853-1862) (C) 2004 American Society for Mass Spectrometry
\end{abstract}

$\mathrm{P}$ olyaromatic amines and nitroarenes are metabolically activated to reactive intermediates by oxidation of the amino group or nitroreduction, respectively. The resulting N-hydroxy or nitroso intermediates form covalent adducts with DNA or proteins $[1,2]$. Dinitropyrenes are among the most mutagenic substances tested [3,4], are carcinogenic in test animals [2] and have been classified as possible human carcinogens by the International Agency for Research on Cancer [5]. Dinitropyrene has been observed in diesel

Published online November 2, 2004

Address reprint requests to Dr. W. Völkel, Department of Toxicology, University of Würzburg, Versbacher Strasse 9, Würzburg 97078, Germany. E-mail: voelkel@toxi.uni-wuerzburg.de exhaust particles, gasoline engine emissions, indoor emissions of kerosene and light gas burners, airplane emissions at airports and emissions from the combustion of plastics. Dinitropyrene was present in photocopier toners until 1980, but improved manufacturing processes resulted in a substantial reduction. Kerosene and light gas burners are not used indoors in Europe or Northern America. Airplane emissions at airports do not contribute significantly to ambient or occupational exposure of the general public and waste combustion is carried out under controlled conditions including the filtration of emissions in Europe or Northern America. Therefore, the only relevant source of human exposure to dinitropyrene is diesel engine exhaust [6-9], which itself has been classified as possible human carcinogen 
[5]. Up to now, a refined risk assessment lacks exact data for human exposure to diesel engine emissions within epidemiological studies. Since diesel engine emissions are a complex mixture, specific and sensitive marker compounds are required for the determination of the internal dose or early biological effects. In the past, exposure assessment of diesel engine emissions has applied a number of early biological effects (e.g., DNA-adducts) and various biomarkers of internal exposure like hemoglobin adducts of 1-nitropyrene or polycyclic hydrocarbons [10-12]. Confounders like diet and/or smoking habits as well as other combustion processes reduce the specificity of these markers [13]. Due to the specificity for diesel engine emissions, we chose dinitropyrene to develop a sensitive analytical method for the analysis of internal doses of dinitropyrene and the metabolites aminonitropyrene and diaminopyrene in blood.

Up to now, dinitropyrene, aminonitropyrene, and diaminopyrene were analyzed mainly by gas chromatography mass spectrometry (GC-MS), liquid chromatography coupled to electrochemical detection (LCECD), chemiluminescence detection (LC-CLD), and fluorescence detection (LC-FLD) methods [14]. Disadvantages of GC-MS are the low volatility of aminopyrenes and the need for excessive sample workup and derivatization of hydrophilic amino groups. However, GC-MS with chemical ionization after derivatization is the most common technique for the detection of hemoglobin adducts of 1-nitrosopyrene [12, 15]. LC-FLD and LC-CLD data with sufficient sensitivity have been published for the analysis of particle extracts, but these methods require on-line reduction of dinitropyrene to diaminopyrene, which represents a very intense fluorophoric system. In biological matrices such as urine and plasma however, other fluorophoric substances are present, making FLD and CLD less specific and thus less sensitive [16].

Therefore, we decided to develop a method based on high performance liquid chromatography coupled to triple quadrupole mass spectrometry (HPLC-MS/ MS), since the use of very specific MS/MS transitions results in an efficient reduction of noise levels. One transition may be applied for quantification purposes and one for the confirmation of the analyte identity. In addition, the possibility to use isotope labeled internal standards provides a method with highest sensitivity and specificity for analyses in biological matrices like urine and plasma as published for analytes like bisphenol A [17]. Only a few data are available on the HPLC-MS/MS behavior of aromatic amines and no data are available for nitroaromatics, which are typical analytes for GC-MS [18]. Difficulties in the separation of ambiphilic aromatic amines by liquid chromatography and small rates of ion formation of nitroaromatics using the common electrospray ionization may be reasons for the neglect of HPLC-MS/MS as analytical tool for this class of compounds. The availability of an atmospheric pressure photoionization (APPI) technique $[19,20]$ for the ionization of more lipophilic compounds offers the opportunity to analyze both aromatic amines and nitroaromatics with high sensitivity in biological matrices. In the present publication, three different ionization techniques (electrospray ionization (ESI), atmospheric pressure chemical ionization (APCI), and atmospheric pressure photoionization (APPI) using commercially available interfaces were compared for the quantitation of dinitropyrene, aminonitropyrene, and diaminopyrene in plasma of rats treated with a mixture of 1,3-, 1,6-, and 1,8-dinitropyrene isomers (Figure 1). Method development criteria were unequivocal analyte identification and optimization of sensitivity of SRM (single reaction monitoring) methods. Validation criteria for the applicability of the most sensitive method to plasma were recovery, limits of detection (LODs) in plasma, linearity of calibration curves up to 500 pg calculated for $10 \mu \mathrm{L}$ plasma (higher concentrations are not anticipated in human samples due to the exposure levels), accuracy and matrix effects on ionization.

\section{Experimental}

\section{Safety considerations}

Dinitropyrenes are suspected human carcinogens and should be handled with care.

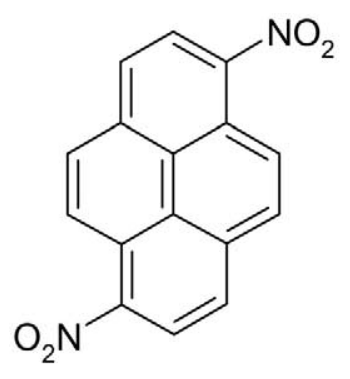

1: $M_{r}=292.3 \mathrm{Da}$<smiles>Nc1ccc2ccc3c([N+](=O)[O-])ccc4ccc1c2c43</smiles>

2: $M_{r}=262.3 \mathrm{Da}$<smiles>Nc1ccc2ccc3c(N)ccc4ccc1c2c43</smiles>

3: $M_{r}=232.3 \mathrm{Da}$

Figure 1. Structures of the analytes: 1,6-dinitropyrene (1), 1,6-aminonitropyrene (2), 1,6-diaminopyrene (3). 


\section{Instrumentation}

HPLC-MS/MS experiments were carried out with an Agilent 1100 autosampler and an Agilent 1100 HPLC system (Agilent Technologies, Waldbronn, Germany) coupled to an API 3000 triple stage quadrupole mass spectrometer equipped with a TIS (turbo ionspray), APCI, or APPI source (Applied Biosystems, Darmstadt, Germany). Alternatively, a Qtrap HPLC-MS/MS system (Applied Biosystems) was used. Analyst 1.3.1 or analyst 1.3.2 was used for instrument control and data analysis (Applied Biosystems).

\section{Reagents}

1,3-, 1,6- and 1,8-Diaminopyrene were obtained from Tokyo Kasai Kogyo Co., Ltd (Tokyo, Japan) and 1-aminopyrene (1-AP) was purchased from Aldrich (Taufkirchen, Germany). 1,6- and 1,8-aminonitropyrene were a kind gift of Dr. Basu (Department of Chemistry, University of Conneticut, Storrs, Conneticut). A mixture of dinitropyrene isomers was synthesized as described by Hashimoto and Shudo [21].

\section{General}

Reversed phase HPLC-MS/MS using ESI, APCI, and APPI as well as normal phase HPLC-MS/MS with APPI were optimized separately with respect to sensitivity and unequivocal analyte identification for quantitative measurement. Experiments to test the efficiency of ionization and to generate fragmentation patterns of the analytes were carried out with all sources applied. A syringe pump was used to provide a constant analyte infusion $(300 \mu \mathrm{L} / \mathrm{h})$ into the HPLC eluent via a Tconnection. Analyte concentrations were chosen in the range of 5-100 ng/ $\mu \mathrm{L}$ to obtain a constant signal in the Q1 scan mode. Basic source and MS parameters such as declustering potential (DP), focussing potential (FP), collision energy (CE), and exit potential (CXP) were optimized using the "quantitative optimization" function of analyst 1.3.1.

\section{Comparison of Methods}

LODs and limits of quantitation (LOQs) were measured in triplicate with the most sensitive method for each source. Precision and accuracy of the instrument was calculated on the basis of 20 consecutive injections of one sample with calibration curves measured in duplicate. The injection volume was $10 \mu \mathrm{L}$. A Luna C8 (2) $3 \mu \mathrm{m}(50 \times 2 \mathrm{~mm})$ HPLC column (Phenomenex, Aschaffenburg, Germany) with a water (Solvent A)/ acetonitrile (Solvent B) gradient (5-90\% B in 2 min, $90-100 \% \mathrm{~B}$ in $4 \mathrm{~min}, 100 \% \mathrm{~B}$ for $1 \mathrm{~min}$ ) and a flow rate of $200 \mu \mathrm{L}$ for reversed phase HPLC and a ReproSilPur $120 \mathrm{CN} 5 \mu \mathrm{m}(150 \times 2 \mathrm{~mm}) \mathrm{HPLC}$ column (Dr. Maisch-GmbH, Ammerbuch, Germany) with an isooctane (A)/isopropanol (B) gradient $(60-80 \%$ B in $5 \mathrm{~min}, 80-100 \% \mathrm{~B}$ in $2 \mathrm{~min}, 100 \% \mathrm{~B}$ for $2 \mathrm{~min}$ ) and a flow rate of $200 \mu \mathrm{L}$ for normal phase HPLC were used. Diaminopyrene, aminonitropyrene, and 1-aminopyrene (1-AP) were quantified in the positive mode, dinitropyrene in the negative mode with nitrogen as collision gas $(\mathrm{CAD}=4)$.

ESI parameters were: ion spray (IS) voltage $4000 \mathrm{~V}$ and source temperature (TEM) $400{ }^{\circ} \mathrm{C}$. Aminonitropyrene isomers were detected with the SRM transition $\mathrm{m} / \mathrm{z}$ $263.1 \rightarrow m / z 216.1$ (DP $31 \mathrm{~V}, \mathrm{CE} 39 \mathrm{~V}$ ) and $\mathrm{m} / \mathrm{z} 263.1 \rightarrow$ $m / z 246.1$ (DP $61 \mathrm{~V}, \mathrm{CE} 23 \mathrm{~V}$ ), 1-aminopyrene with the SRM transition $m / z 218.2 \rightarrow m / z 201.1$ (DP $81 \mathrm{~V}$, CE $39 \mathrm{~V}$ ) and $m / z 218.2 \rightarrow m / z 202.2$ (DP $81 \mathrm{~V}$, CE $39 \mathrm{~V}$ ). The dwell time for each SRM was $500 \mathrm{~ms}$.

APCI parameters were: needle current (NC) 3 and TEM $400{ }^{\circ} \mathrm{C}$. Aminonitropyrene isomers were detected with the SRM transition $m / z 263.1 \rightarrow m / z 216.3$ (DP $25 \mathrm{~V}$, CE $37 \mathrm{~V}$ ) and $m / z 263.1 \rightarrow m / z 246.3$ (DP $25 \mathrm{~V}, \mathrm{CE} 23 \mathrm{~V}$ ), 1-aminopyrene with the SRM transition $\mathrm{m} / \mathrm{z} 218.4 \rightarrow \mathrm{m} / \mathrm{z}$ 202.3 (DP $25 \mathrm{~V}, \mathrm{CE} 36 \mathrm{~V}$ ) and $\mathrm{m} / \mathrm{z} 218.4 \rightarrow \mathrm{m} / z$ 201.1 (DP $25 \mathrm{~V}, \mathrm{CE} 24 \mathrm{~V})$ and dinitropyrene isomers with the SRM transition $m / z 292.1 \rightarrow m / z 262.0(\mathrm{DP}-31 \mathrm{~V}, \mathrm{CE}-24 \mathrm{~V})$ and $m / z 292.1 \rightarrow m / z 232.0(\mathrm{DP}-31 \mathrm{~V}, \mathrm{CE}-34 \mathrm{~V}$ ). The dwell time for each SRM was $500 \mathrm{~ms}$.

APPI parameters were: source voltage (IS) $1500 \mathrm{~V}$ and TEM $450{ }^{\circ} \mathrm{C}$. Aminonitropyrene isomers were detected with the SRM transition $\mathrm{m} / \mathrm{z} 263.1 \rightarrow \mathrm{m} / \mathrm{z} 216.3$ (DP $25 \mathrm{~V}, \mathrm{CE} 37 \mathrm{~V}$ ) and $m / z 263.1 \rightarrow m / z 246.3$ (DP $25 \mathrm{~V}$, CE $23 \mathrm{~V}), 1$-aminopyrene with the SRM transition $\mathrm{m} / \mathrm{z}$ $218.4 \rightarrow m / z 202.3$ (DP $25 \mathrm{~V}$, CE $36 \mathrm{~V}$ ), and $m / z 218.4 \rightarrow$ $\mathrm{m} / z 201.1$ (DP $25 \mathrm{~V}, \mathrm{CE} 24 \mathrm{~V}$ ) and dinitropyrene isomers with the SRM transition $m / z 292.1 \rightarrow m / z 262.0$ (DP -31 $\mathrm{V}, \mathrm{CE}-24 \mathrm{~V}$ ) and $\mathrm{m} / \mathrm{z} 292.1 \rightarrow \mathrm{m} / z 232.0$ (DP -31 V, CE $-36 \mathrm{~V})$ The dwell time for aminonitropyrene SRMs was $1000 \mathrm{~ms}$, for 1-aminopyrene and dinitropyrene $100 \mathrm{~ms}$.

\section{Plasma Analysis}

Normal phase HPLC-MS/MS connected to APPI was the method with lowest LODs (see the Results and Discussion section) and was chosen for the analysis of plasma samples.

\section{In Vivo Experiments}

Male Lewis rats were treated with $3.5 \mathrm{mg} / \mathrm{kg}$ b.w. dinitropyrene by gavage (in tricaprylin) or by intratracheal instillation (in $0.9 \% \mathrm{NaCl}, 5 \%$ ethanol). Animals were sacrificed by $\mathrm{CO}_{2}$ asphyxiation $24 \mathrm{~h}$ after treatment and blood samples were collected by cardiac puncture. Plasma was separated from red blood cells by centrifugation $(3000 \mathrm{~g})$ and stored at $-20{ }^{\circ} \mathrm{C}$ until further sample workup.

\section{Optimization of Recovery from Plasma}

Plasma samples of control animals $(100 \mu \mathrm{L})$ were spiked with 1,6- and 1,8-aminonitropyrene (10 pg) and dinitropyrene mixture (100 pg). Extraction efficiency with 
isooctane $(100 \mu \mathrm{L})$ or isopropanol/isooctane (1:1; vol: vol, $100 \mu \mathrm{L})$ was evaluated with or without $\mathrm{pH}$ adjustment to alkaline $\mathrm{pH}$ by addition of $5 \%$ ammonia $(2 \mu \mathrm{L})$. The upper organic phase was directly injected. Alternatively, protein was precipitated from spiked plasma by addition of methanol and acetonitrile and subsequent centrifugation at $3500 \mathrm{~g}$ for $15 \mathrm{~min}$. The supernatant was evaporated to dryness by vacuum centrifugation, redissolved in isopropanol/isooctane (1:1; vol:vol, $100 \mu \mathrm{L})$ and submitted to analysis. Recovery was determined comparing signal areas with those of a standard solution of $10 \mathrm{pg} / 100 \mu \mathrm{L}$ aminonitropyrene and $100 \mathrm{pg} / 100$ $\mu \mathrm{L}$ dinitropyrene in isopropanol/isooctane (1:1; vol: vol). The best compromise for all substances (aminonitropyrene $20 \%$, dinitropyrene $100 \%$ ) was the extraction with isopropanol/isooctane $(1: 1$; vol:vol) without $\mathrm{pH}$ adjustment.

\section{LOD, Accuracy, and Matrix Effects}

Matrix effects on ionization efficiency were examined for 1,8-aminonitropyrene comparing standard solutions and plasma extracts spiked with the same amount of analytes after extraction to exclude an effect of sample workup. The LOD in spiked plasma was determined in duplicate. The calibration curve was measured in duplicate from 5-500 pg/100 $\mu \mathrm{L}$ plasma for 1,8-aminonitropyrene and from $10-500 \mathrm{pg} / 100 \mu \mathrm{L}$ plasma for 1,8-dinitropyrene. Precision and accuracy of the method was determined with plasma samples spiked with 1,8-dinitropyrene and 1,8-aminonitropyrene (tenfold above the LOD, $\mathrm{n}=5$ ) to plasma of controls.

\section{Results and Discussion}

\section{Ionization and Fragmentation}

Unequivocal analyte identification and optimization of sensitivity of SRM methods required an understanding of ionization mechanisms using the different ionization sources and of fragmentation patterns. Full scan and product ion spectra were recorded during infusion experiments with a LC eluent of $350 \mu \mathrm{L} / \mathrm{min}$ with pure water or two different $\mathrm{pH}$ values $(\mathrm{pH} 10.5$ and $\mathrm{pH} 3)$. Observed precursor and fragment ions are given in Table 1. No differences in ionization patterns were encountered using different HPLC solvents except for electrospray ionization of diaminopyrenes (Table 1). The observed differences in fragmentation between 1,6and 1,8-diaminopyrene versus 1,3-diaminopyrene can be explained by different resonance stabilization energies of the cations.

Upon APCI and APPI, precursor ions of reduced mass were observed $\left(\left[\mathrm{M}-30+\mathrm{H}^{+}\right.\right.$for aminonitropyrene and $[\mathrm{M}-30]^{-}$or $[\mathrm{M}-30+\mathrm{H}]^{+}$for dinitropyrene) besides the expected ones-namely a protonated precursor ion for aminonitropyrene [M + $\mathrm{H}]^{+}$and a radical anion for dinitropyrene $\left[\mathrm{M}^{-}\right]^{-}$. The precursor ions of reduced mass had the same $m / z$ as the metabolites aminonitropyrene and diaminopyrene. To guarantee unequivocal analyte identification based upon MS/MS data, the generation of these precursor ions should be prevented. For HPLC-MS/MS measurements with APCI, $[\mathrm{M}-30+\mathrm{H}]^{+}$precursor ions for aminonitropyrene could be reduced but not completely eliminated by the use of pure water as polar solvent as opposed to $5 \mathrm{mM}$ ammonium acetate $(\mathrm{pH} 3)$. A generation of $[\mathrm{M}-30+\mathrm{H}]^{+}$during or before the analytical column can be excluded since these compounds are observed at the retention time of aminonitropyrene.

$\mathrm{A}[\mathrm{M}+\mathrm{H}]^{+} /[\mathrm{M}-30+\mathrm{H}]^{+}$ratio $>1$ for aminonitropyrene could not be achieved by variation of needle current (NC: 1, 3, and 5) and source temperature (TEM: $300{ }^{\circ} \mathrm{C}$ and $400{ }^{\circ} \mathrm{C}$ ) during an infusion of 1,6 -aminonitropyrene $(2 \mathrm{ng} / \mu \mathrm{L}$ at a syringe pump rate of $900 \mu \mathrm{L} / \mathrm{h}$, LC eluent of $95 \%$ AcCN/5\% water, Q1 scan). Increasing NC settings resulted in increasing intensities of $[\mathrm{M}+$ $\mathrm{H}]^{+}$and $[\mathrm{M}-30+\mathrm{H}]^{+}$in the Q1 scan. However, no influence on the ratio $[\mathrm{M}+\mathrm{H}]^{+} /[\mathrm{M}-30+\mathrm{H}]^{+}$was observed. For a source temperature of $400{ }^{\circ} \mathrm{C}$ the ratio $[\mathrm{M}+\mathrm{H}]^{+} /[\mathrm{M}-30+\mathrm{H}]^{+}$was always smaller than 1 . For $300{ }^{\circ} \mathrm{C}$ the ratio equaled 1 , but overall intensities were lower than at $400{ }^{\circ} \mathrm{C}$. Since a further increase in occurrence of $[\mathrm{M}-30+\mathrm{H}]^{+}$with higher temperatures was to be prevented, $400{ }^{\circ} \mathrm{C}$ was chosen for further experiments.

The occurrence of $[\mathrm{M}-30+\mathrm{H}]^{+}$in APPI measurements could be decreased by the use of aprotic solvent systems, a clean glass liner, and increasing temperatures. This indicates that the generation of precursor ions of reduced mass $\left([\mathrm{M}-30+\mathrm{H}]^{+}\right.$and $\left.[\mathrm{M}-30]^{-}\right)$ of aminonitropyrene and dinitropyrene is a surface catalyzed process involving reactive species from protic solvents $[22,23]$.

\section{Sensitivity}

Electrospray ionization. Calibration curves of diaminopyrene and aminonitropyrene isomers were measured in duplicate for $\mathrm{pH} 3$ and 10.5 and, for aminonitropyrene, additionally with pure water as polar mobile phase constituent. With 50\% $0.1 \mathrm{~N} \mathrm{NaOH}$ in AcCN (vol/vol) as sample solvent, isomers of diaminopyrene could be detected with higher sensitivity compared with aminonitropyrene isomers at a concentration of 50 pg/10 $\mu \mathrm{L}$. At $10 \mathrm{pg} / 10 \mu \mathrm{L}$, a more than linear decrease in sensitivity for the detection of diaminopyrene was observed; thus, diaminopyrene isomers could not be detected below $10 \mathrm{pg} / 10 \mu \mathrm{L}$. An explanation might be a decrease in electrolytic oxidation in ESI in low concentrations: One of the prerequisites for a quantitative oxidation is sufficient availability of analyte at the metal surface which, among others, is a function of analyte concentration [24]. Alternatively, the observed more than linear decrease in sensitivity might result from the fact that relative to the small analyte concentration, many sites for unwanted strong silanol-amine interaction are available on the HPLC column. This would lead 
Table 1. Precursor ions and fragment ions of diaminopyrene (DAP), aminonitropyrene (ANP) and dinitropyrene (DNP) generated by ESI, APCI, and-APPI. The cited references give explanations for the observed fragments

\begin{tabular}{|c|c|c|c|c|c|}
\hline $\begin{array}{l}\text { Compound } \\
\text { of interest }\end{array}$ & $\begin{array}{l}\text { Observed } \\
\text { precursor lons }\end{array}$ & Possible explanations & References & Observed fragments & \\
\hline \multicolumn{6}{|l|}{ ESI } \\
\hline \multirow[t]{4}{*}{ DAP } & {$\left[\mathrm{M}^{\cdot}\right]^{+} \mathrm{m} / \mathrm{z} 232(\mathrm{pH} 3)$} & $\begin{array}{l}\text { electrolytic oxidation (charge } \\
\text { balance requirements in } \\
\text { ESI) }\end{array}$ & [36-38] & $\begin{array}{l}{\left[\mathrm{M}-2 \mathrm{NH}_{2}+2 \mathrm{H}_{2}\right]^{+}} \\
{\left[\mathrm{M}-\mathrm{NH}_{2}-\mathrm{CHNH}_{2}\right.} \\
\left.\quad+\mathrm{H}_{2}\right]^{+}\end{array}$ & $\begin{array}{l}m / z 204 \\
m / z 189\end{array}$ \\
\hline & $\begin{array}{l}{[\mathrm{M}-\mathrm{H}]^{+}} \\
10.5)\end{array}$ & $\begin{array}{l}\text { electrolytic oxidation by } \mathrm{H}^{+} \\
\text {abstraction }\end{array}$ & & $\begin{array}{l}{\left[\mathrm{M}-\mathrm{NH}_{2}\right]^{+}} \\
{\left[\mathrm{M}-2 \mathrm{NH}_{2}+2 \mathrm{H}_{2}+\right.} \\
\quad \mathrm{H}]^{+}\end{array}$ & $\begin{array}{l}m / z 216 \\
m / z 204\end{array}$ \\
\hline & & $\begin{array}{l}\text { two electron oxidation } \\
\text { followed by } \mathrm{H}^{+} \text {abstraction }\end{array}$ & [39] & $\begin{array}{l}{\left[\mathrm{M}-\mathrm{NH}_{2}-\mathrm{CHNH}_{2}\right.} \\
\left.\quad+\mathrm{H}_{2}+\mathrm{H}\right]^{+}\end{array}$ & $m / z 189$ \\
\hline & & $\begin{array}{l}\text { protonation followed by } \mathrm{NH}_{2} \\
\text { abstraction }\end{array}$ & {$[40,41]$} & {$\left[\mathrm{M}-\mathrm{NH}_{2}+\mathrm{H}\right]^{+}$} & $m / z 216$ \\
\hline $\begin{array}{l}\text { 1,6- and } \\
\text { 1,8-DAP }\end{array}$ & $\begin{array}{l}{[\mathrm{M}+\mathrm{H}]^{+} \mathrm{m} / \mathrm{z} 233, \text { low }} \\
\quad \text { abundance }\end{array}$ & protonation & & $\begin{array}{l}{\left[\mathrm{M}-\mathrm{NH}_{2}^{+}+\mathrm{H}\right]^{+}} \\
{\left[\mathrm{M}-\mathrm{NH}_{3}-\mathrm{CHNH}_{2}\right.} \\
\left.\quad+\mathrm{H}_{2}\right]^{+}\end{array}$ & $\begin{array}{l}m / z 217 \\
m / z\end{array}$ \\
\hline 1,3-DAP & $\begin{array}{l}{[\mathrm{M}+\mathrm{H}]^{+} \mathrm{m} / \mathrm{z} 233 \text {, low }} \\
\quad \text { abundance }\end{array}$ & protonation & & $\begin{array}{l}{\left[\mathrm{M}-\mathrm{NH}_{3}+\mathrm{H}\right]^{+}} \\
{\left[\mathrm{M}-\mathrm{NH}_{3} \mathrm{CHNH}_{2}+\right.} \\
\left.\quad \mathrm{H}_{2}\right]^{+}\end{array}$ & $\begin{array}{l}m / z 216 \\
m / z\end{array}$ \\
\hline ANP & {$[\mathrm{M}+\mathrm{H}]^{+} m / z 263$} & protonation & & {$\left[\mathrm{M}-\mathrm{NH}_{3}+\mathrm{H}\right]^{+}$} & $m / z 246$ \\
\hline \multirow[t]{2}{*}{ DNP } & $\begin{array}{l}{[\mathrm{M}+\mathrm{H}]^{-} \mathrm{m} / \mathrm{z} 293} \\
\quad \text { very low abundance }\end{array}$ & $\begin{array}{l}\text { hydrogeneration followed by } \\
\text { deprotonation }\end{array}$ & & n.p. & \\
\hline & & $\begin{array}{l}\text { electrolytic reduction by } \mathrm{H}^{+} \\
\text {(charge balance } \\
\text { requirements in } \mathrm{ESI})\end{array}$ & {$[36]$} & & \\
\hline \multicolumn{6}{|l|}{ APCl, APPI } \\
\hline DAP & {$[\mathrm{M}+\mathrm{H}]^{+} m / z 233$} & protonation & & $\begin{array}{c}\text { comparable to DAP } \\
{[\mathrm{M}+\mathrm{H}]^{+} \text {in ESI }}\end{array}$ & \\
\hline \multirow[t]{2}{*}{ ANP } & {$[\mathrm{M}+\mathrm{H}]^{+} \mathrm{m} / \mathrm{z} 263$} & protonation & & $\begin{array}{l}\text { comparable to ANP } \\
\text { in ESI }\end{array}$ & \\
\hline & {$[\mathrm{M}-30+\mathrm{H}]^{+} \mathrm{m} / \mathrm{z} 233$} & $\begin{array}{l}\text { loss of NO / in-source } \\
\text { reduction }\end{array}$ & {$[23,42,43]$} & $\begin{array}{l}\text { comparable to DAP } \\
\text { in APCl, APPI }\end{array}$ & \\
\hline \multirow[t]{7}{*}{ DNP } & {$\left[\mathrm{M}^{\prime}\right]^{-} \mathrm{m} / \mathrm{z} 292$} & electron capture & {$[42]$} & {$[\mathrm{M}-\mathrm{NO}]^{-}$} & $m / z 262$ \\
\hline & & & & {$[\mathrm{M}-2 \mathrm{NO}]^{-}$} & $\mathrm{m} / \mathrm{z} 232$ \\
\hline & & & & {$\left[\mathrm{M}-\mathrm{NO}-\mathrm{NO}_{2}\right]^{-}$} & $\begin{array}{l}m / z 216 \\
m / z 216\end{array}$ \\
\hline & {$[\mathrm{M}-30]^{-} \mathrm{m} / \mathrm{z} 262$} & $\begin{array}{l}\text { loss of } \mathrm{NO} / \text { in-source } \\
\text { reduction }\end{array}$ & {$[23,42,43]$} & $\begin{array}{l}{\left[\mathrm{M}-\mathrm{NO}_{2}\right]^{-}} \\
{[\mathrm{M}-\mathrm{NO}]^{-}}\end{array}$ & $\begin{array}{l}m / z 216 \\
m / z 232\end{array}$ \\
\hline & {$[\mathrm{M}-59]^{-} \mathrm{m} / \mathrm{z} 233$} & $\begin{array}{l}\text { loss of } \mathrm{NO} / \text { in-source } \\
\text { reduction }(2 \times) \\
\text { deprotonation, } \\
\text { hydrogenation }\end{array}$ & & n.p. & \\
\hline & {$[\mathrm{M}-30+\mathrm{H}]^{+} \mathrm{m} / z 263$} & $\begin{array}{l}\text { loss of } \mathrm{NO} / \text { in-source } \\
\text { reduction, protonation }\end{array}$ & & $\begin{array}{l}\text { comparable to ANP } \\
\text { in APCl, APPI }\end{array}$ & \\
\hline & {$[\mathrm{M}-60+\mathrm{H}]^{+} \mathrm{m} / \mathrm{z} 233$} & $\begin{array}{l}\text { loss of NO/or in-source } \\
\text { reduction }(2 \times) \\
\text { protonation }\end{array}$ & & $\begin{array}{l}\text { comparable to DAP } \\
\text { in APCI, APPI }\end{array}$ & \\
\hline
\end{tabular}

to a cut-off concentration below which diaminopyrene will not reach the detector as a narrow peak. At high concentrations, where many of those sites are blocked by a small percentage of the analyte, the remaining analyte may reach the detector as a peak. For aminonitropyrene isomers, there was no difference in sensitivity between $\mathrm{pH} 3$ and 10.5. However, aminonitropyrene was detected with higher sensitivity with pure water than with buffers as polar mobile phase constituent in ESI. A concentration of $100 \mathrm{pg} / 10 \mu \mathrm{L}$ 1,8-dinitropyrene was below the LOD.

Atmospheric pressure chemical ionization. A comparison of calibration curves for aminonitropyrene measured in duplicate with pure water versus $5 \mathrm{mM}$ ammonium acetate $(\mathrm{pH} 3)$ as polar solvents gave higher sensitivity with water. There was no indication of $[\mathrm{M}-30+\mathrm{H}]^{+}$ precursor ions after injection of low concentrations of aminonitropyrene. Therefore, LOD and LOQ of aminonitropyrene and dinitropyrene were determined with water as polar solvent using the SRM of $[\mathrm{M}+\mathrm{H}]^{+}$for aminonitropyrene and $[\mathrm{M}]^{-}$for dinitropyrene (Table 2). For diaminopyrene, $5 \mathrm{mM}$ ammonium acetate $(\mathrm{pH} 3)$ in relation to pure water yielded higher sensitivities when high concentration samples were injected. At concentrations lower than $10 \mathrm{pg} / 10 \mu \mathrm{L}$, again a peak broadening was observed for diaminopyrene as seen with ESI at pH 3. 
Atmospheric pressure photoionization. Since the generation of precursor ions of reduced mass is a competing mechanism to the generation of $[\mathrm{M}+\mathrm{H}]^{+}$for aminonitropyrene and $[\mathrm{M}]^{-}$for dinitropyrene, avoidance of the first is of advantage with respect to unequivocal analyte identification as well as for sensitivity enhancement. Therefore, the influence of the dopant flow (with toluene as dopant), the source temperature, and the mobile phase composition on the generation of the different precursor ions was evaluated for minimization of precursor ions with reduced mass in APPI measurements.

The dopant flow rate was optimized by infusion experiments in steps of $0.5 \mathrm{~mL} / \mathrm{h}$ from 0 to $3 \mathrm{~mL} / \mathrm{h}$. The intensity of all observed precursor ion species increased with enhanced dopant flow up to $1.5 \mathrm{~mL} / \mathrm{h}$, which is $10 \%$ of the LC flow rate. With higher dopant flow rates, the intensity levelled off. In general, for dopant assisted ionization, $5-10 \%$ dopant flow versus LC flow rate appears to be optimum [25]. Since the intensity of all observed precursor ion species increased with dopant flow rate up to $1.5 \mathrm{~mL} / \mathrm{h}$, it might be concluded that dopant assisted ionization occurs after the processes leading to precursor ions of reduced mass and that both reactions do not compete with each other.

The dopant flow had no influence on optimum DP and FP settings. Optimum DP and FP values for $[\mathrm{M}+$ $\mathrm{H}]^{+}$and $[\mathrm{M}]^{-}$were lower than those for precursor ions with reduced mass. Infusion of all analytes at 400 and $450{ }^{\circ} \mathrm{C}$ with a dopant flow of $1.5 \mathrm{~mL} / \mathrm{h}$ resulted in higher abundance of compound related ions in full scan spectra at $450{ }^{\circ} \mathrm{C}$ (data not shown). Therefore, a source temperature of $450{ }^{\circ} \mathrm{C}$ and dopant flow rate of $1.5 \mathrm{~mL} / \mathrm{h}$ were chosen for further experiments.

\section{Comparison of Sources}

Ionization. Electrospray ionization of diaminopyrene produced mainly $[\mathrm{M}]^{+}\left(\right.$or $\left.[\mathrm{M}-\mathrm{H}]^{+}\right)$, whereas $[\mathrm{M}+$ $\mathrm{H}]^{+}$was the most abundant precursor ion in APCI and APPI. This may be explained by charge-balance requirements in ESI leading to an oxidation of diaminopyrene in the positive mode. This is supported by the absence of an abundant $[\mathrm{M}]^{+}$in APCI, since no electrolytic oxidation to fulfil charge-balance requirements occurs in APCI and APPI due to an ionization in the gas phase outside the electric circuit [24]. The lack of $[\mathrm{M}]^{+}$ion formation for aminonitropyrene in electrospray ionization might be explained by a higher oxidation potential of aminonitropyrene compared with diaminopyrene and by the -I-effect of the nitro group, reducing the stabilization abilities of a radical cation produced by electrolytic oxidation.

The lack of extensive ionization of dinitropyrene in ESI is due to the absence of proton accepting or proton donating functional groups. The negatively charged radical ions observed in APCI and APPI are due to electron accepting capabilities of the nitroaromatic system. Generation of precursor ions of reduced mass for aminonitropyrene and dinitropyrene was similar for APCI and APPI. Kertesz and van Berkel [22] described comparable results for the in-source reduction of electropolymerized aniline using APCI and APPI.

Sensitivity. For the determination of LODs and LOQs the SRM with highest intensities was used after "quantitative optimization" of all SRMs for each source. At concentrations close to the LOD, $[\mathrm{M}-30]^{-}$ and $[\mathrm{M}-30+\mathrm{H}]^{+}$ions were not detectable, so that $[\mathrm{M}]^{-}$and $[\mathrm{M}+\mathrm{H}]^{+}$species were used for APCI and APPI measurement.

Diaminopyrene isomers could not be analyzed in low concentrations with the methods evaluated, which is attributed to unsatisfactory chromatographic behavior. During infusion experiments, MS/MS sensitivity of diaminopyrene detection was similar to that of aminonitropyrene.

The highest sensitivity for the measurement of aminonitropyrene and dinitropyrene was obtained with normal phase HPLC-MS/MS using APPI at the highest temperature available and a dopant flow rate of 1.5 $\mathrm{mL} / \mathrm{h}$ (Table 2). APPI is also more sensitive than APCI or ESI for other compounds such as steroids or polyaromatic hydrocarbons (PAH) [26-28]. In fact, Robb et al. found APPI the only suitable ionization source for the LC-MS analysis of PAH [19]. Since nitro groups have strong electron withdrawing capacities, the non-dissociative electron capture ionization in APCI might be possible for dinitropyrene but not for PAHs. Impey et al. showed, that in some cases normal phase HPLC-

Table 2. Comparison of LODs [pg/10 $\mu \mathrm{L}$ ] (S/N in brackets) and precision calculated on the basis of 20 replicate measurements of one sample within one day (concentration $[\mathrm{pg} / 10 \mu \mathrm{L}]$ in brackets) for reversed phase (RP) or normal phase (NP) HPLC connected to ESI, APCI, and APPI

\begin{tabular}{|c|c|c|c|c|c|c|c|c|}
\hline & \multicolumn{2}{|c|}{ ESI } & \multicolumn{2}{|c|}{$\mathrm{APCl}$} & \multicolumn{4}{|c|}{ APPI } \\
\hline & \multirow[b]{2}{*}{ LOD } & \multirow[b]{2}{*}{$\% \mathrm{cv}$} & \multirow[b]{2}{*}{ LOD } & \multirow[b]{2}{*}{$\% \mathrm{cv}$} & \multicolumn{2}{|c|}{$\mathrm{RP}$} & \multicolumn{2}{|c|}{ NP } \\
\hline & & & & & LOD & $\% \mathrm{cV}$ & LOD & $\% \mathrm{cv}$ \\
\hline 1-AP & $10(4)$ & $12(20)$ & $5(5)$ & $12(20)$ & $-*$ & $-*$ & $-*$ & -* $^{*}$ \\
\hline 1,8-ANP & $5(3)$ & $8(20)$ & $0.3(3)$ & $6(20)$ & $0.2(3)$ & $8(2)$ & $0.1(5)$ & $6(1)$ \\
\hline 1,8-DNP & $-^{*}$ & $-*$ & $50(5)$ & $15(200)$ & $0.5(5)$ & $17(2)$ & $0.2(4)$ & $9(1)$ \\
\hline
\end{tabular}

*: not performed, 1-AP: 1-aminopyrene, ANP: aminonitropyrene, DNP: dinitropyrene. 
MS/MS using APPI yields LODs 4-80 times lower than with reversed phase HPLC [29]. Sensitivity enhancement in APPI with increasing temperatures is explained by reduced aerosol droplet sizes resulting in an enhanced analyte and solvent evaporation [30, 31]. Another explanation is the elimination of hydrogen radicals without water responsible for the occurrence of precursor ions of reduced mass. The generation of these ions competes with that of $[\mathrm{M}]^{-}$and $[\mathrm{M}+\mathrm{H}]^{+}$ions.

\section{LC Separation}

In general, the interpretation of fragmentation patterns of standards and the use of two typical SRM transitions provides an unequivocal analyte identification. Since the occurrence of precursor ions of reduced mass for aminonitropyrene and dinitropyrene could not be completely eliminated and a similar fragmentation pattern was observed for aminonitropyrene and diaminopyrene as shown in Figure 2 such an unequivocal analyte identification could not be guaranteed without LCseparation.

Therefore, an MRM method including sensitive SRMs for both $[\mathrm{M}+\mathrm{H}]^{+}$and $[\mathrm{M}-30+\mathrm{H}]^{+}$was created with $1 \mathrm{ng} / 10 \mu \mathrm{L}$ of each analyte injected individually to give unequivocal identification of analytes

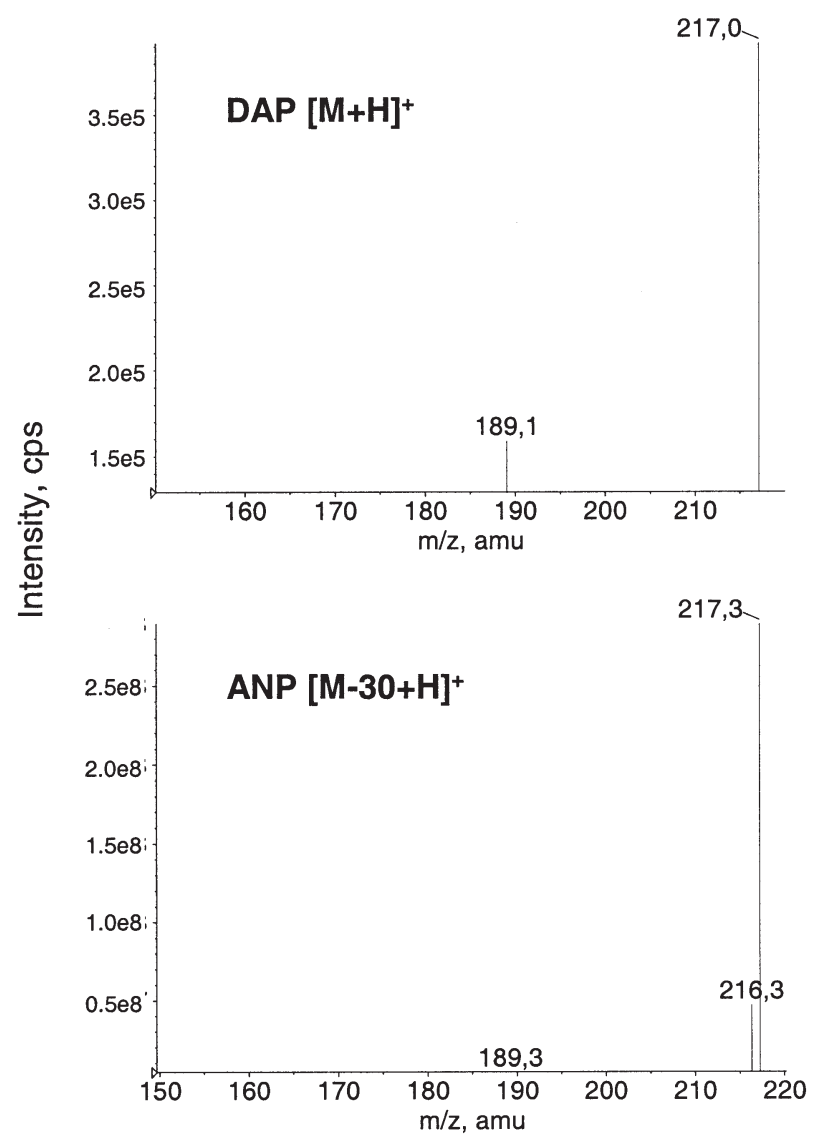

Figure 2. Similar product ion spectra of $[\mathrm{M}+\mathrm{H}]^{+}$of diaminopyrene and $[\mathrm{M}-30+\mathrm{H}]^{+}$of aminonitropyrene in APCI.

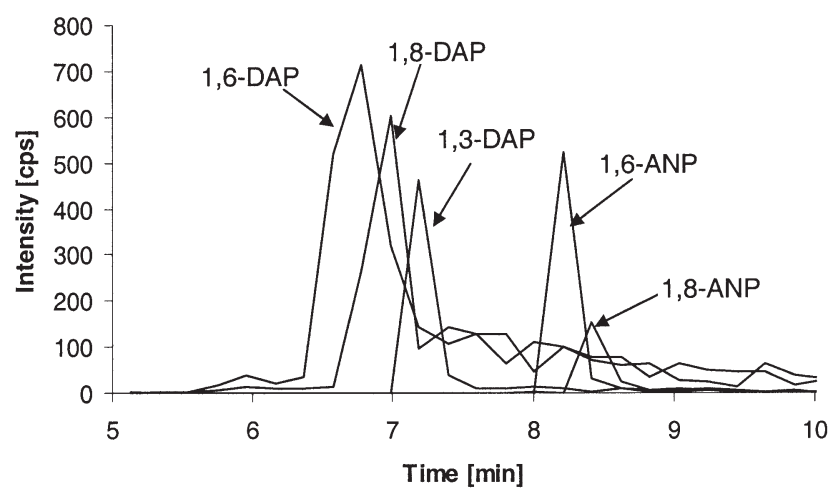

Figure 3. Separation of 1,3-, 1,6-, and 1,8-diaminopyrene as well as 1,6- and 1,8-aminonitropyrene by HPLC on Luna C8 (2) $150 \times$ $2 \mathrm{~mm}$.

by establishing different retention times. On a Luna C 8 (2) $150 \times 2 \mathrm{~mm}$ column, diaminopyrene and aminonitropyrene isomers have different retention times (RT) with pure water as solvent $\mathrm{A}$ during gradient elution (5-90\% B in $2 \mathrm{~min}, 90-100 \%$ B in $8 \mathrm{~min}, 100 \%$ B for 1 min) (Figure 3). Unfortunately, this method was less sensitive compared with normal phase HPLC-MS/MS method (see the Experimental section). The aminonitropyrene peak at $3.4 \mathrm{~min}$ including all isomers could be separated from the dinitropyrene peak at $3.0 \mathrm{~min}$ by normal phase HPLC, but neither dinitropyrene isomers nor aminonitropyrene isomers were resolved (Figure $4 b)$.

Chromatographic behavior of diaminopyrene iso-

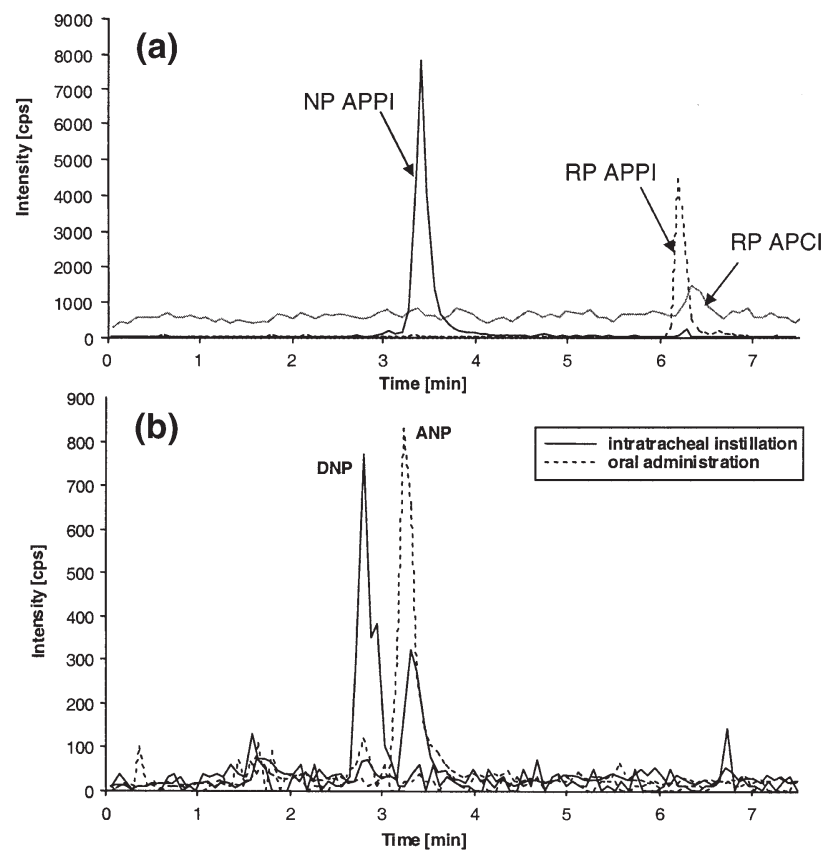

Figure 4. (a) LC-MS/MS chromatogram of $10 \mathrm{pg} / 10 \mu \mathrm{L}$ aminonitropyrene for different sources and normal phase (NP) versus reversed phase (RP) HPLC; (b) NP-HPLC-MS/MS chromatogram with APPI for plasma samples after oral or intratracheal administration of dinitropyrene. 
mers was poor due to peak broadening, asymmetric peak shapes, and irreproducible retention times. Different HPLC columns and mobile phase compositions were tested to improve chromatography. Best results were obtained at alkaline $\mathrm{pH}$ and on polar endcapped, polar modified or ultra pure columns with high surface coverage. This chromatographic behavior of diaminopyrene is explained by unwanted interactions of protonated or unprotonated amino groups with unmodified silanol groups of stationary phases. Therefore, chromatography of diaminopyrene was worse at low $\mathrm{pH}$ values than at neutral or alkaline $\mathrm{pH}$ values, due to a higher degree of protonation. HPLC material which is not endcapped resulted in worsening chromatographic behavior of diaminopyrene isomers. In addition, the use of polar embedded or polar endcapped phases or of quantitatively endcapped silica improved chromatography slightly, and in experiments with APCI the use of $\mathrm{NaOH}$ as sample solvent improved chromatography since protonated amines were eliminated. With reversed phase HPLC LODs below $10 \mathrm{pg} / 10 \mu \mathrm{L}$ were not obtained for diaminopyrene. Due to the lower degree of chemical modification of normal stationary phases compared with reversed phase materials, the separation with normal phases resulted in the complete lack of signals for diaminopyrene isomeres. Therefore, using the most sensitive normal phase APPI method for the detection of dinitropyrene and aminonitropyrene, the unequivocal identification was not compromised by the presence of diaminopyrene.

\section{Precision and Accuracy}

When comparing the different ionization techniques and reversed phase versus normal phase HPLC for APPI (Figure 4a), normal phase HPLC-MS/MS with APPI resulted in highest sensitivity and precision for both aminonitropyrene and dinitropyrene using standard solutions (Table 2). Therefore, this method was used for the determination of dinitropyrene and aminonitropyrene in plasma of rats treated with dinitropyrene.

The LOD for spiked plasma was $5 \mathrm{pg} / 100 \mu \mathrm{L}$ plasma equalling $0.5 \mathrm{pg} / 10 \mu \mathrm{L}$ on column for aminonitropyrene. This was slightly higher than the LOD using standard solutions due to lower recovery. Calibration curves were linear from 5-500 pg/100 $\mu \mathrm{L}$ plasma for 1,8 -aminonitropyrene with $\mathrm{R}^{2}=0.991$ and from $10-500$ pg/100 $\mu \mathrm{L}$ plasma for 1,8-dinitropyrene with $\mathrm{R}^{2}=$ 0.993. The presence of plasma matrix enhanced APPI efficiency for 1,8-aminonitropyrene by about 100\%. Therefore, precision and accuracy was determined in plasma samples of control animals spiked with 1,8aminonitropyrene and 1,8-dinitropyrene (at a level of 10 $\times$ LOD). Five or six samples were separately analyzed, and the precision was $<7 \%$ for both analytes (Table 3 ). The accuracy was determined with calibration curves of control plasma spiked with six different concentrations of 1,8-aminonitropyrene and 1,8-dinitropyrene, respec- tively. No isotope labeled standard was used for internal calibration. The accuracy was better than $100 \pm 4 \%$ (Table 3). Samples have to be analyzed directly after sample preparation since accuracy becomes worse if samples of Day 1 were analyzed at Day 2. Interestingly, an increase in concentration was observed in this case. However, precision was still high with a coefficient of variation of $<8 \%$.

\section{In Vivo Experiment}

As a proof of concept, rats were exposed to a mixture of dinitropyrene isomers $(3.5 \mathrm{mg} / \mathrm{kg}$ b.w.) by oral or intratracheal instillation. In plasma samples of these rats, aminonitropyrene metabolites could be detected in contrast to plasma of controls with concentrations of 37 pg/100 $\mu \mathrm{L}$ plasma after oral and of $19 \mathrm{pg} / 100 \mu \mathrm{L}$ plasma after intratracheal application. Dinitropyrene isomers were only detected after intratracheal instillation with $90 \mathrm{pg} / 100 \mu \mathrm{L}$ plasma. Since the most sensitive normal phase HPLC-MS/MS method with APPI was used for detection, a separation of the individual isomers of both analytes was not possible (Figure $4 \mathrm{~b}$ ). Nevertheless, the data clearly show that dinitropyrene was assimilated and nitroreduced after intratracheal and oral application but the extent of nitroreduction of dinitropyrene to aminonitropyrene was lower after intratracheal application.

The lack of dinitropyrene detection after oral application may be explained by a high first pass effect of reductive liver enzymes after resorption of dinitropyrene from the intestinal tract or by a contribution of intestinal bacteria to the reductive metabolism. These indicated differences in biotransformation of dinitropyrene should be studied in the future using the analytical methods described and should be taken into account when using data from animals treated by oral administration for the risk assessment of diesel engine emissions.

\section{Conclusions}

To our knowledge, this is the first time that a systematic comparison of different LC-MS sources is presented for the detection of polyaromatic amines and nitro compounds. Dinitropyrene, aminonitropyrene, and diaminopyrene were selected as model compounds for other

Table 3. Accuracy and precision for sample preparation and quantitation by normal phaseHPLC-MS/MS with APPI. Five or six spiked control plasma samples (10 fold LOD) were separately analyzed for precision and the accuracy was calculated by an internal calibration curve $(n=6)$ without internal standard

\begin{tabular}{lllll}
\hline & $\begin{array}{c}\text { Precision } \\
\text { (day 1) }\end{array}$ & $\begin{array}{c}\text { Precision } \\
\text { (day 2) }\end{array}$ & Accuracy & $\mathrm{R}^{2}$ \\
\hline \hline 1,8-ANP & $4 \%(n=6)$ & $4 \%(n=5)$ & $98 \%-102 \%$ & 0.999 \\
1,8-DNP & $7 \%(n=6)$ & $3 \%(n=5)$ & $96 \%-104 \%$ & 0.997 \\
\hline
\end{tabular}


polyaromatic amines and nitro compounds for which biomonitoring methods are required and due to the specificity for diesel engine exhaust. Especially with APPI, the detection of amino and/or nitro aromatic compounds should be possible by LC-MS without any further sample work up necessary for other methods based on GC-MS or HPLC.

Compared with other HPLC methods published in the literature [32], aminonitropyrene can be determined with higher sensitivity without an on-line reduction of dinitropyrene or aminonitropyrene to diaminopyrene, which has to be done for FLD or CLD measurement [33-35]. Furthermore, the FLD or CLD methods were exclusively used for the detection of dinitropyrene in diesel engine emissions or urban air particulate matter but not in biological matrices such as plasma or urine containing other fluorescent compounds. In addition, a discrimination between dinitropyrene and aminonitropyrene is not possible with the on-line reduction assay resulting in a lower specificity and sensitivity of FLD and CLD. The specificity of MS/MS reduces the need for extensive sample preparation providing low LODs with good accuracy and precision in plasma. Compared with GC-MS, the method described is more specific and no extensive sample workup inculding derivatization procedures is necessary. However, the instrumental sensitivity of the method is lower. Since more steps in sample workup may cause a loss of analyte, the LCMS/MS method presented may be comparably sensitive to GC-MS with a higher degree of specificity. A detection of dinitropyrene and aminonitropyrene in plasma samples of humans exposed to high levels of diesel engine emissions (i.e., tunnel workers or miners) may be possible after a specific sample enrichment procedure. An exposure assessment for dinitropyrene is not available so far. Therefore, it is not possible to calculate the LOD of the method necessary for the detection of dinitropyrene derived biomarkers in humans. On the other hand, the data show clearly that the analytical method is easily applicable to mechanistic studies in animal models, in vitro studies, and to other polyaromatic nitro or amino compounds such as 1-aminopyrene.

\section{Acknowledgments}

This work was supported by Forschungsvereinigung Automobiltechnik e.V. (FAT) and by the German Scholarship Foundation (Studienstiftung des deutschen Volkes). The authors thank Mr. Gérard Hopfgartner for carefully reading this manuscript.

\section{References}

1. Sabbioni, G.; Jones, C. R. Biomonitoring of Arylamines and Nitroarenes. Biomarkers 2002, 7, 347-421.

2. Fu, P. P.; Herreno-Saenz, D. Nitro-Polycyclic Aromatic Hydrocarbons: A Class of Genotoxic Environmental Pollutants. Environ. Carcino. Ecotox. Revs. 1999, C17, 1-43.
3. Rosenkranz, H. S.; Mermelstein, R. Mutagenicity and Genotoxicity of Nitroarenes. All Nitro-Containing Chemicals were not Created Equal. Mutat. Res. 1983, 114, 217-267.

4. Tokiwa, H.; Ohnishi, Y. Mutagenicity and Carcinogenicity of Nitroarenes and Their Sources in the Environment. Crit. Rev. Toxicol. 1986, 17, 23-60.

5. International Agency for Research on Cancer: Diesel and Gasoline Engine Exhausts and Some Nitroarenes. In: I.A.f.R.o. Cancer (Ed.), Monographs on the Evaluation of the Carcinogenic Risks to Humans. Lyon, France, 1989.

6. Schuetzle, D. Sampling of Vehicle Emissions for Chemical Analysis and Biological Testing. Environ. Health Perspect. 1983, $47,65-80$.

7. Gibson, T. L. Sources of Direct-Acting Nitroarene Mutagens in Airborne Particulate Matter. Mutat. Res. 1983, 122, 115-121.

8. Manabe, Y.; Kinouchi, T.; Ohnish, Y. Identification and Quantification of Highly Mutagenic Nitroacetoxypyrenes and Nitrohydroxypyrenes in Diesel-Exhaust Particles. Mutat. Res. 1985, 158, 3-18.

9. Nakagawa, R.; Kitamori, S.; Horikawa, K.; Nakashima, K.; Tokiwa, H. Identification of Dinitropyrenes in Diesel-Exhaust Particles. Their Probable Presence as the Major Mutagens. Mutat. Res. 1983, 124, 201-211.

10. Scheepers, P. T.; Micka, V.; Muzyka, V.; Anzion, R.; Dahmann, D.; Poole, J.; Bos, R. P. Exposure to Dust and ParticleAssociated 1-Nitropyrene of Drivers of Diesel-Powered Equipment in Underground Mining. Ann. Occup. Hyg. 2003, 47, 379-388.

11. Seidel, A.; Dahmann, D.; Krekeler, H.; Jacob, J. Biomonitoring of Polycyclic Aromatic Compounds in the Urine of Mining Workers Occupationally Exposed to Diesel Exhaust. Int. J. Hyg. Environ. Health 2002, 204, 333-338.

12. Zwirner-Baier, I.; Neumann, H. G. Polycyclic Nitroarenes (Nitro-PAHs) as Biomarkers of Exposure to Diesel Exhaust. Mutat. Res. 1999, 441, 135-144.

13. Scheepers, P. T.; Coggon, D.; Knudsen, L. E.; Anzion, R.; Autrup, H.; Bogovski, S.; Bos, R. P.; Dahmann, D.; Farmer, P.; Martin, E. A.; Micka, V.; Muzyka, V.; Neumann, H. G.; Poole, J.; Schmidt-Ott, A.; Seiler, F.; Volf, J.; Zwirner-Baier, I. Biomarkers for Occupational Diesel Exhaust Exposure Monitoring (BIOMODEM)-A Study in Underground Mining. Toxicol. Lett. 2002, 134, 305-317.

14. Hayakawa, K. Chromatographic Methods for Carcinogenic/ Mutagenic Nitropolycyclic Aromatic Hydrocarbons. Biomed. Chromatogr. 2000, 14, 397-405.

15. Sabbioni, G.; Beyerbach, A. Haemoglobin Adducts of Aromatic Amines: Diamines and Polyaromatic Amines. J. Chromatogr. B. Biomed. Sci. Appl. 2000, 744, 377-387.

16. van Bekkum, Y. M.; van den Broek, P. H.; Scheepers, P. T.; Bos, R. P. Sensitive and Selective Detection of Urinary 1-Nitropyrene Metabolites Following Administration of a Single Intragastric Dose of Diesel Exhaust Particles (SRM 2975) to Rats. Chem. Res. Toxicol. 1998, 11, 1382-1390.

17. Volkel, W.; Colnot, T.; Csanady, G. A.; Filser, J. G.; Dekant, W. Metabolism and Kinetics of Bisphenol A in Humans at Low Doses Following Oral Administration. Chem. Res. Toxicol. 2002, 15, 1281-1287.

18. Bayona, J. M.; Barcelo, D.; Albaiges, J. Characterization of Polar Substituted Polycyclic Aromatic Compounds Using High-Resolution Gas Chromatography/Mass Spectrometry Negative Ion Chemical Ionization and Positive and Negative Ion Thermospray Liquid Chromatography/Mass Spectrometry. Biomed. Environ. Mass Spectrom. 1988, 16, 461-467.

19. Robb, D. B.; Covey, T. R.; Bruins, A. P. Atmospheric Pressure Photoionization: An Ionization Method for Liquid Chromatography-Mass Spectrometry. Anal. Chem. 2000, 72, 3653-3659. 
20. Syage, J. A.; Evans, M. D. Photoionization Mass Spectrometry. A Powerful New Tool for Drug Discovery. Spectroscopy 2001, $16,14-21$.

21. Hashimoto, Y.; Shudo, K. Preparation of Pure Isomers of Dinitropyrenes. Chem. Pharm. Bull. 1984, 32, 1992-1994.

22. Kertesz, V.; Van Berkel, G. Surface-Assisted Reduction of Aniline Oligomers, N-Phenyl-1,4-Phenylenediimine and Thionin in Atmospheric Pressure Chemical Ionization and Atmospheric Pressure Photoionization. J. Am. Soc. Mass Spectrom. 2002, 13, 109-117.

23. Budzikiewicz, H. Reactions Between Substrate Molecules and Chemical Ionization Reagent Gases Prior to Ionization. Org. Mass Spectrom. 1988, 23, 561-565.

24. van Berkel, G. J. The Electrolytic Nature of Electrospray. In: Electrospray Ionization Mass Spectrometry; Cole, R. B., Ed.; John Wiley and Sons: New York, 1997; p 577.

25. Photospray Ion Source; Operator's Manual. Applied Biosystems and MDS Sciex: Concord, Canada, 2002, pp 1-52.

26. Robb, D. B.; Bruins, A. P.; Peters, H. A. M.; Jacobs, P. L. Atmospheric Pressure Photoionization (APPI) for High Sensitivity LC/MS in Bioanalysis. Proceedings of the 48th ASMS Conference on Mass Spectrometry and Allied Topics; Long Beach, CA, 2000, p 14.

27. Alary, J.-F. Comparative Study: LC-MS/MS Analysis of Four Steroid Compounds Using a New Photoionization Source and a Conventional APCI Source. Proceedings of the 49th ASMS Conference on Mass Spectrometry and Allied Topics; Chicago, IL, 2001, p 9.

28. Trosken, E. R.; Straube, E. A.; Patten, C.; Lutz, W. K.; Voelkel, W. Quantitation of Lanosterol and Its Major Metabolite FFMAS in an Inhibition Assay of CYP51 by Azoles with Atmospheric Pressure Photoionization Based LC-MS/MS. J. Am. Soc. Mass Spectrom., 2004, 15 1216-1221.

29. Impey, G.; Kieser, G.; Alary, J.-F. The Analysis of Polycyclic Aromatic Hydrocarbons (PAH) by LC/MS/MS Using a New Atmospheric Pressure Photoionization Source. Proceedings of the 49th ASMS Conference on Mass Spectrometry and Allied Topics; Chicago, IL, 2001, p 187.

30. Takino, M.; Daishima, S.; Nakahara, T. Determination of Perfluorooctane Sulfonate in River Water by Liquid Chromatography/Atmospheric Pressure Photoionization Mass Spectrometry by Automated On-Line Extraction Using Turbulent Flow Chromatography. Rapid Commun. Mass Spectrom. 2003, 17, 383-390.

31. Takino, M.; Daishima, S.; Nakahara, T. Liquid Chromatography/Mass Spectrometric Determination of Patulin in Apple
Juice Using Atmospheric Pressure Photoionization. Rapid Commun. Mass Spectrom. 2003, 17, 1965-1972.

32. Korfmacher, W. A.; Rushing, L. G.; Engelbach, R. J.; Freeman, J. P.; Djuric, Z.; Fifer, E. K.; Beland, F. A. Analysis of Three Aminonitropyrene Isomers via Fused Silica Gas Chromatography Combined with Negative Ion Atmospheric Pressure Ionization Mass Spectrometry. J. High Resolut. Chromatogr., Chromatogr. Commun. 1987, 10, 43-45.

33. Hayakawa, K.; Terai, N.; Dinning, P. G.; Akutsu, K.; Iwamoto, Y.; Etoh, R.; Murahashi, T. An On-Line Reduction HPLC/ Chemiluminescence Detection System for Nitropolycyclic Aromatic Hydrocarbons and Metabolites. Biomed. Chromatogr. 1996, 10, 346-350.

34. Watanabe, T.; Ishida, S.; Kishiji, M.; Takahashi, Y.; Furuta, A.; Kasai, T.; Wakabayashi, K.; Hirayama, T. High-Performance Liquid Chromatography-Fluorescence Determination of Dinitropyrenes in Soil After Column Chromatographic Clean-Up and On-Line Reduction. J. Chromatogr. A 1999, 839, 41-48.

35. Hayakawa, K.; Kitamura, R.; Butoh, M.; Imaizumi, N.; Miyazaki, M. Determination of Diamino- and Aminopyrenes by High Performance Liquid Chromatography with Chemiluminescence Detection. Anal. Sci. 1991, 7, 573-577.

36. van Berkel, G. J. In: Electrospray Ionization Mass Spectrometry; Cole, R. B., Ed.; John Wiley and Sons: New York, 1997; p 577.

37. van Berkel, G. J.; McLuckey, S. A.; Glish, G. L. Anal. Chem. 1992, 64, 1586-1593.

38. Blades, A. T.; Ikonomou, M. G.; Kebarle, P. Mechanism of Electrospray Mass Spectrometry. Electrospray as an Electrolysis Cell. Anal. Chem. 1991, 63, 2109-2114.

39. van Berkel, G. J.; Zhou, F. Chemical Electron-Transfer Reactions in Electrospray Mass Spectrometry: Effective Oxidation Potentials of Electron-Transfer Reagents in Methylene Chloride. Anal. Chem. 1994, 66, 3408-3415.

40. Budzikiewicz, H. Spectros. Int. J. 1987, 5, 183.

41. Volkel, W.; Wolf, N.; Derelanko, M.; Dekant, W. Slow Oxidation of Acetoxime and Methylethyl Ketoxime to the Corresponding Nitronates and Hydroxy Nitronates by Liver Microsomes from Rats, Mice, and Humans. Toxicol. Sci. 1999, 47, $144-150$.

42. Hayen, H.; Jachmann, N.; Vogel, M.; Karst, U. LC-Electron Capture APCI-MS for the Determination of Nitroaromatic Compounds. Analyst 2002, 127, 1027-1030.

43. Karancsi, T.; Slegel, P. Reliable Molecular Mass Determination of Aromatic Nitro Compounds: Elimination of Gas-Phase Reduction Occurring During Atmospheric Pressure Chemical Ionization. J. Mass Spectrom. 1999, 34, 975-977. 